\title{
Novel transportation capsule technology could reduce the exposure risk to SARS-CoV-2 infection among healthcare workers: A feasibility study
}

\author{
Basel Almuabbadi RN, Huda Mhawish MSc RN, Bobby Marasigan RN, Alva Alcazar RN, Zahraa Alfrdan RN, \\ Nasir Nasim MD, Abdulrahman Alharthy MD, Ziad A. Memish MD FACP and Dimitrios Karakitsos MD, PhD (1) \\ Critical Care Department, King Saud Medical City, Riyadh, Saudi Arabia
}

To the Editor-Previous studies have documented high infection rates of healthcare workers (HCWs) with severe acute respiratory coronavirus virus 2 (SARS-CoV-2) during the current coronavirus disease 2019 (COVID-19) pandemic. ${ }^{1-4}$ Apart from the routine bedside care, HCWs are exposed to the risk of SARS-CoV-2 cross infection during the transportation of COVID-19 patients. In our healthcare facility, King Saud Medical City (Riyadh, Saudi Arabia), we have employed the recently developed transportation capsule Epi-Shuttle (Epi-guard AS, Torsnesvein, Norway) to reduce the aforementioned risk during the transportation of COVID-19 patients to and from the intensive care unit (ICU). No data exist in the literature regarding this technology. Briefly, the transportation capsule is an innovative, single-patient, isolation system composed of cleanable materials protecting patients from contaminated environments and protecting HCWs from infected patients. The capsule is compatible with standard mechanical ventilation circuits integrating negative- and positive-pressure technology and protective filters against cross contamination by highly infectious pathogens. In the negative-pressure mode, the isolation system protects HCWs from the contaminated air particles shed by infected patients, and in positive-pressure mode, it protects patients from hazardous environmental agents. The recommended disinfection solution for cleaning the capsule after each use is peracetic acid, according to the manufacturer. ${ }^{5}$ We are reporting our preliminary experience using this new technology.

The ICU of King Saud Medical City (Riyadh, Saudi Arabia) is a 200-bed polyvalent unit designated by the Saudi Ministry of Health (MOH) for the treatment of COVID-19 patients. As of April 2020, 480 patients with COVID-19 had been admitted to our unit, including 380 critically ill patients and 100 patients with moderate-to-serious disease. At that time, we had transported 190 critically ill COVID-19 patients from our healthcare facility to other COVID-19-targeted hospitals according to the Saudi $\mathrm{MOH}$ surge plan. The tactical plan has been constantly reviewed and adjusted based on the influx of COVID-19 cases in our ICU. All data were collected and retrospectively analyzed. Of these 190 transported patients, 100 patients had been intubated and 90 patients were on oxygen-supportive therapies. Also, $109 \mathrm{HCWs}$ were employed for the transportation of COVID-19 patients: 39

Author for correspondence: Dr Dimitrios Karakitsos, Critical Care Dept., King Saud Medical City, Work address: PO Box 331905, Zip code: 11373 - Shemaisi, Riyadh, Saudi Arabia. Phone: +966-509816296, E-mail: karakitsosdimitrios@gmail.com

Cite this article: Almuabbadi B, et al. (2021). Novel transportation capsule technology could reduce the exposure risk to SARS-CoV-2 infection among healthcare workers: A feasibility study. Infection Control \& Hospital Epidemiology, 42: 788-789, https:// doi.org/10.1017/ice.2020.352

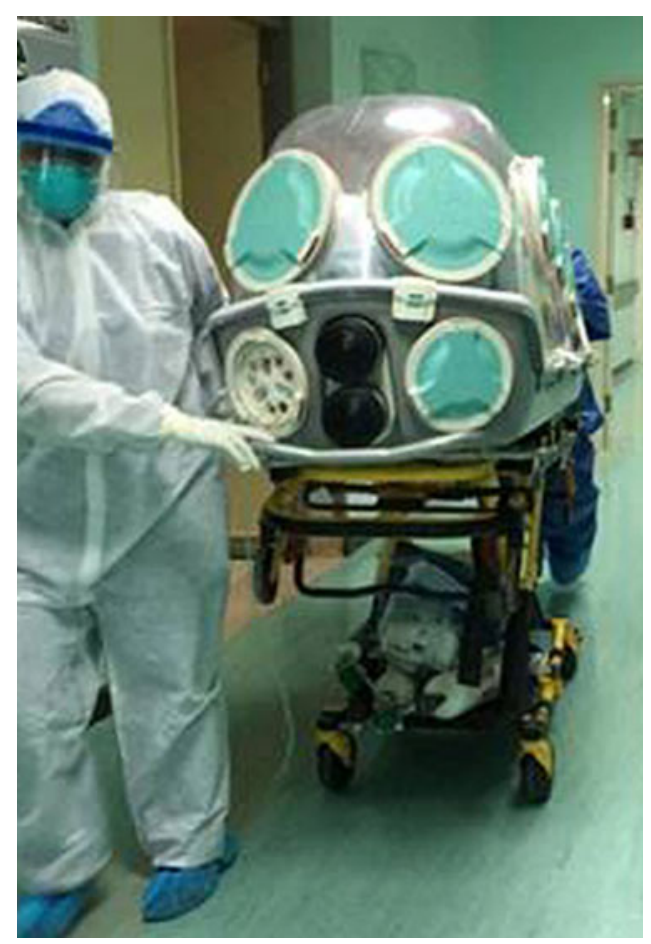

Fig. 1. Our healthcare workers transporting a critically ill COVID-19 patient using the insulated capsule.

physicians, 20 respiratory physiotherapists, 20 ICU nurses, and 30 paramedics (Fig. 1). Apart from utilizing the capsule, all HCWs used personal protective equipment according to the World Health Organization recommendations. ${ }^{5}$ None of the 109 HCWs became infected. Moreover, all awake (ie, nonintubated) patients reported a high level of comfort during transportation. Full treatment of ICU patients via access ports, which facilitated emergency procedures (eg, intubation and insertion of central lines) has been possible. In conclusion, the insulated patient capsule has proven to be an efficient technology for the transportation of COVID-19 patients. The capsule has shown good compatibility with ventilator circuits and full treatment of ICU patients as well as ambulance stretchers. Most importantly, none of our HCWs was infected in the transportation process. Large prospective studies are required to confirm or refute the present findings.

Acknowledgments. None.

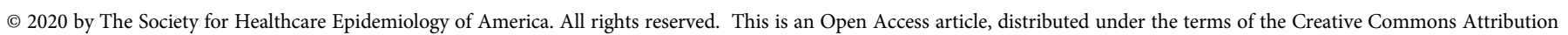
licence (http://creativecommons.org/licenses/by/4.0/), which permits unrestricted re-use, distribution, and reproduction in any medium, provided the original work is properly cited. 
Financial support. No financial support was provided relevant to this article.

Conflicts of interest. All authors report no conflicts of interest relevant to this article.

\section{References}

1. Tostmann A, Bradley J, Bousema T, et al. Strong associations and moderate predictive value of early symptoms for SARS-CoV-2 test positivity among healthcare workers, the Netherlands, March 2020. Euro Surveill 2020;25: 2000508.

2. Lo D. COVID-19: protecting health-care workers. Lancet 2020;395:922.

3. Cheng V, Wong S-C, Chen J, et al. Escalating infection control response to the rapidly evolving epidemiology of the coronavirus disease 2019 (COVID-19) due to SARS-CoV-2 in Hong Kong. Infect Control Hosp Epidemiol 2020;41:493-498.
4. Ng K, Poon BH, Kiat Puar TH, et al. COVID-19 and the risk to healthcare workers: a case report. Ann Intern Med (in press). doi: 10.7326/ L20-0175.

5. EpiGuard-medical isolation and transportation systems. Epiguard website. https://epiguard.com/. Accessed April 22, 2020.

6. Coronavirus disease (COVID-19) outbreak: rights, roles and responsibilities of health workers, including key considerations for occupational safety and health interim guidance, 19 March 2020. World Health Organization website. https:/www.who.int/publications-detail/coronavirus-disease-(covid-19)outbreak-rights-roles-and-responsibilities-of-health-workers-including-keyconsiderations-for-occupational-safety-and-health. Published March 19, 2020. Accessed July 20, 2020.

\title{
COVID-19 and ophthalmology: An underappreciated occupational hazard
}

\author{
Anadi Khatri MD ${ }^{1}$, Muna Kharel MD², Babu Dhanendra Chaurasiya $M^{3}$, Ashma K.C. MD ${ }^{4}$ and \\ Bal Kumar Khatri MD 5 \\ ${ }^{1}$ Birat Eye Hospital, Biratnagar, Province 1, Nepal, ${ }^{2}$ Nepalese Army Institute of Health Sciences, Kathmandu, Province 3, Nepal, ${ }^{3} \mathrm{Narayani}$ Hospital, Birgunj, \\ Province 2, Nepal, ${ }^{4}$ Bharatpur Eye Hospital, Bharatpur, Province 3, Nepal and ${ }^{5}$ Kakarvitta Eye Centre, Kakarvitta, Province 1, Nepal
}

Letter to the Editor-We read the article "COVID-19 and ophthalmology: an underappreciated occupational hazard" by Kuo and $\mathrm{O}^{\prime} B$ Brien $^{1}$ with great interest. They have described the challenges faced by eye care personnel during this pandemic very well in a systematic manner. We would like to add few of our own experiences.

Personal protective equipment (PPE) has become the gold standard during the COVID-19 pandemic for prevention of infection. Although it has its advantages, many problems may arise in terms of comfort and ease in certain circumstances. Currently, with much of the primary focus on infection prevention, these may often be overlooked. In the long term, these difficulties may hamper the performance of healthcare workers like ophthalmologists, whose work demands high precision. As lockdowns are easing and services are resuming, we present our report from a pilot study we conducted in Nepal among ophthalmologists on this matter. We conducted a small survey among 24 ophthalmologists who had recently ( $<1$ week) returned to work using PPE. They were asked to describe issues related to discomfort or difficulty in performing regular tasks when using PPE. They were also asked to grade on a Likert scale of 1 to 5 ( 1 least likely to 5 most likely) the issues they considered were most troubling (Table 1).

Returning to work after weeks of furlough only to suddenly and be enshrouded in PPE is a new challenge for many of us. Although it has become a norm, the evidence is already clear that many ophthalmologists and eye care professionals are having difficulties related to PPE use. ${ }^{2}$ Although the evidence is concrete on infection prevention with its use, ${ }^{3}$ our results suggest that PPE may need to be redesigned and customized to best fit the activity or the demands of

Author for correspondence: Anadi Khatri, E-mail: anadikc@gmail.com

Cite this article: Khatri A, et al. (2021). COVID-19 and ophthalmology: An underappreciated occupational hazard. Infection Control \& Hospital Epidemiology, 42: 789-790, https://doi.org/10.1017/ice.2020.344
Table 1. Problems Related to Discomfort and Difficulty in Performing Regular Examination for Ophthalmologists With Use of Personal Protective Equipment ${ }^{a}$

\begin{tabular}{lcc}
\hline Problems & $\begin{array}{c}\text { Frequency, } \\
\text { No. (\%) }\end{array}$ & $\begin{array}{c}\text { Problem Scale } \\
\text { (Mode values) }\end{array}$ \\
\hline Thermal discomfort/sweating & $18(75)$ & 3 \\
\hline Muffled voice (unable to understand) & $22(91.6)$ & 3 \\
\hline Fogging & $19(79.1)$ & 5 \\
\hline Difficulty in using slit lamps & $10(41.6)$ & 4 \\
\hline $\begin{array}{l}\text { Difficulty in focusing using face } \\
\text { shields }\end{array}$ & $17(70.8)$ & 5 \\
\hline Unsure of DIY protectives/shields & $15(62.5)$ & 4 \\
\hline
\end{tabular}

${ }^{\text {aT }}$ Total participants $=24$.

b 14 of the 24 participants were spectacle users; all complained of fogging.

individual workers. Problems like fogging, sweating, and difficulty focusing are unacceptable not only in ophthalmological but many other faculties related to high-precision procedures. With more evidence that COVID-19 is here to stay, ${ }^{4}$ these problems will continue to hinder efforts to restart or continue services.

Physical distancing often tops the list and is the most prioritized advise during this pandemic. However, due to the nature of examination, it is practically impossible for eye care professionals to adopt it. ${ }^{1,5}$ In addition to PPE, improvised, low-tech, "Do it yourself" (DIY) protective devices are also being widely used. ${ }^{6}$ Although this may be an advantage because much of the "design for the greatest ease of use" would have already been already improvised, many such DIY efforts remain unproven in terms of the actual protection they provide. Until tested for its "quantifiable" protection value, physicians may fall into the trap of "pseudo" protection and confidence in their use. 